\section{IMPACT OF CHILDHOOD CHRONIC ILLNESSES ON SIBLINGS: A SYSTEMATIC LITERATURE REVIEW}

\section{O’Brien}

\section{School of Nursing and Midwifery, Trinity College Dublin, Dublin, Ireland}

Background: Childhood chronic illness can have a significant impact on siblings of ill children. The aim of this review was to identify, appraise and synthesise the literature in order to examine the impact of childhood chronic illness or disability on siblings.

Method: A systematic review was undertaken by searching the databases CINAHL, PsycINFO, ProQuest and Cochrane Library. By using relevant search terms seventeen research studies were reviewed. All of the studies used quantitative methodologies to examine the impact of childhood chronic illness on siblings.

Results: The review focused on three sibling groups related to children diagnosed with autism, cancer and Down's syndrome. The findings are discussed under the following headings: 'sibling adjustment to chronic illness', 'family functioning and sibling's coping resources' and finally 'intervention programmes for siblings of chronically ill children'.

Conclusion: The literature revealed that siblings of children with Down's syndrome were well adjusted to living with their brother or sister. However, there was conflicting information on the adjustment of siblings of children diagnosed with Cancer and Autism. An awareness of the harmful effect that living with childhood illness and disability can have on some siblings is essential to enable children's nurses to provide supportive interventions to protect siblings' physical and emotional wellbeing.

Keywords: Autism, Cancer, Children's nursing, Chronic illness, Disability, Siblings

\section{PARENTS' EXPERIENCES OF A NEONATAL HOME CARE PROGRAM}

\author{
E. Hammarstrand ${ }^{1}$, L. Jönsson ${ }^{2}$, I. Hallström² \\ ${ }^{1}$ PICU, Skane University Hospital, ${ }^{2}$ Division of \\ Nursing, Department of Health Sciences, Lund \\ University, Lund, Sweden
}

Background: During the years 2002-2005 three hundred and ninety infants, who were physiologically stable but in need of further special care, participated in a neonatal home care program at Lund University Hospital in Sweden. On an average, each infant spent 17 days in the programme and received a mean of 4,6 home visits. When estimating the costs neonatal home care was found to be less expensive than the traditional hospital care. The aim of this study was to describe parents' experiences of the neonatal home care program.

Method: Qualitative data collection was used. Six mothers and four fathers were individually interviewed about their experiences of being included in the neonatal home care program. Textual data, from transcribed audiotapes, was analyzed with qualitative content analysis.

Results: Parents were positive to care for their children at home. They described a process where the responsibility for the child went from the staff at the hospital to the parents at home. In caring for their child at hospital they felt vulnerable and incompetent. At home they felt comfortable and became gradually more confident.

Conclusion: Neonatal home care is feasible with support of staff from the neonatal unit. According to the parents it activates the family's own resources and normalise the family life. The parents' participation during the hospitalisation can further be developed and this can maybe decrease the infants' lengths of stay at hospital. 